\title{
NMR Study on Microscopic Pore Characteristics of Coals of Different Coal Ranks
}

\author{
Jiajia Liu ${ }^{1,2,3}$, Jianliang Gao ${ }^{1,2,3}$, Ming Yang1,2,3 \\ ${ }^{1}$ The Collaborative Innovation Center of Coal Safety Production of Henan Province \\ Jiaozuo, China \\ ${ }^{2}$ State Key Laboratory Cultivation Base for Gas Geology and Gas Control \\ Jiaozuo, China \\ ${ }^{3}$ School of Safety Science and Engineering, Henan Polytechnic University \\ Jiaozuo, China \\ liujiajia@hpu.edu.cn; gao@hpu.edu.cn; yming@hpu.edu.cn
}

\section{Extended Abstract}

The microscopic pore structure of coal directly affects the adsorption and permeability of coal, while the coals of different coal ranks have significantly different microscopic pore structures. In this paper, the microscopic pore structure difference of coals of different ranks was studied by combining low temperature liquid nitrogen and nuclear magnetic resonance technology. The results showed that the desorption curve of high rank coal (ZM) was significantly inflected at $\left(0.5 \mathrm{P} / \mathrm{P}_{0}\right)$ and that of medium/low rank coal $(\mathrm{XJ}, \mathrm{HB}, \mathrm{SX})$ was not inflected at $\left(0.5 \mathrm{P} / \mathrm{P}_{0}\right)$. High rank coal contains more "inkbottle"-shaped pores and slit pores, with complex pore system and poor connectivity between pores; while lowlintermediate rank coal contains more open pores, with simple pore system and good connectivity between pores. NMR test showed that the micro pores $(<10 \mathrm{~nm})$ of low/medium rank coal accounted for about $20 \%$ of the total pores, which was significantly lower than that of high rank coal (about 70\%); however, the macro pores of low/medium rank coal accounted for about $10 \%$ of the total pores, which was higher than that of high rank coal. The $\mathrm{T}_{2}$ spectrum of low-rank coal (XJ) presents a continuous threepeak distribution, and the total area of $\mathrm{T}_{2}$ spectrum is 13400 (dimensionless). The $\mathrm{T}_{2}$ spectrum of medium rank coal (HB, SX) shows bimodal and trimodal distribution (where bimodal distribution is dominant), with a total area of $\mathrm{T}_{2}$ spectrum being 3040. High coal rank (ZM) presents a bimodal distribution, with a total area of $\mathrm{T}_{2}$ spectrum of 19080. This study provides a theoretical basis for the exploration and development of coal bed gas and the safety production of coal mine.

Keywords: Different coal rank, pore structure, microstructure, low temperature liquid nitrogen, NMR.

\section{References}

[1] Z. H. Chen, Y. B. Wang, Y. Song, H. L. Liu, "Comparison of adsorption and desorption characteristics of coalbed methane in different coal ranks," Natural Gas Industry, vol. 28, no. 3, pp. 30-32, 2008.

[2] X. J. Chen, J. Liu, L. Wang, L. L. Qi, "Influence of pore size distribution of different metamorphic grade of coal on adsorption constant," Journal of China Coal Society, vol. 38, no. 2, pp. 294-300, 2013.

[3] Y. Cheng, D. Z. Tang, H. Xu, S. Tao, "Pore and fracture characteristics of different rank coals in the eastern margin of the Ordos Basin," Journal of Natural Gas Science and Engineering, no. 26, pp. 1264-1277, 2015.

[4] L. L. Guo, D. Z. Tang, H. Xu, S. Li, "Analysis on physical property features of different coal rank coal reservoirs in western Guizhou and eastern Yunnan area," Coal Science and Technology, vol. 42, no. 8, pp. 99-103, 2014.

[5] F. L. Li, B. Jiang, Y. Song, Z. Tang, "Nano scale pore structure and fracture characteristics of low-medium metamorphic tectonically deformed coal," Natural Gas Geoscience, vol. 28, no. 1, pp. 173-182, 2017.

[6] A. H. Liu, X. H. Fu, W. Q. Liang, L. Lu, "Pore distribution features of different rank coal and influences to coal bed methane development," Coal Science and Technology, vol. 41, no. 4, pp. 104-108, 2013. 
[7] L. Meng, Y. D. Jiang, Y. X. Zhao, "Investigation on Pore Structure Characteristics of Coal from North China," Coal engineering, vol. 46, no. 6, pp. 118-120, 124, 2014.

[8] Z. H. Qu, B. Jiang, J. L. Wang, "Study of nanopores of tectonically deformed coal based on liquid nitrogen adsorption at low temperatures," Journal of nanoscience and nanotechnology, vol. 17, no. 9, pp. 6566-6575, 2017.

[9] X. H. Shi, J. N. Pan, Q. I. Hou, Y. Jin, "Micrometer-scale fractures in coal related to coal rank based on micro-CT scanning and fractal theory," Fuel, vol. 212, pp. 162-172, 2018.

[10] D. Y. Song, B. Y. Song, C. H. Li, L. Yuan, "Difference in nanopore structure between bituminous coal and high-grade anthracite caused by magmatic intrusion," Journal of nanoscience and nanotechnology, vol. 17, no. 9, pp. 6692-6699, 2017.

[11] S. H. Tang, C. Cai, B. C. Zhu, J. Duan, "Control effect of coal metamorphism on coal reservoir properties," Natural Gas Industry, vol. 28, no. 12, pp. 30-33, 2008.

[12] Q. W. Wang, "Migration pathway discrepancy study of CBM in coal reservoirs with different coal ranks," Coal Geology of China, vol. 24, no. 4, pp. 24-26+30, 2012.

[13] L. Wang, D. Z. Tang, H. Xu, T. X. Yu, "Influence of metamorphism on micropores in coal seams based on nitrogen adsorption experiment," Coal Science and Technology, vol. 42, no. S1, pp. 256-260, 2014.

[14] K. Y. Wang, G. Du, Y. J. Yang, S. T. Dong, "Application of scanning electron microscopy and X-ray energy spectrometer to study the pores of black shale reservoirs in northern Fujian and mineral characteristics," Rock and mineral analysis, vol. 33, no. 5, pp. 634-639, 2014.

[15] S. Wang, J. N. Pan, Y. W. Ju, "The super-micropores in macromolecular structure of tectonically deformed coal using high-resolution transmission electron microscopy," Journal of nanoscience and nanotechnology, vol. 17, no. 9, pp. 6982-6990, 2017.

[16] S. B. Xie, Y. B. Yao, J. J. Chen, "Research of micro-pore structure in coal reservoir using low-field NMR," Journal of China Coal Society, no. 40, pp. 170-176, 2015.

[17] F. Z. Yan, S. H. Tang, N. J. Fang, B. C. Zhu, "Porosity Features of coal deposits in Gaojiazhuang block of Qin shui basin," Coal Science and Technology, vol. 37, no. 2, pp. 103-107, 2009.

[18] Y. B. Yao, D. M. Liu, Y. D. Cai, J. Q. Li, "Fine quantitative characterization of pore cracks in coal based on NMR and X-CT," Science China Press, vol. 40, no. 17, pp. 1598-1607, 2010.

[19] S. H. Zhang, S. H. Tang, D. Z. Tang, Z. F. Yan, "Fractal characteristics of coal reservoir seepage pore east margin of Ordos basin," Journal of China University of Mining \& Technology, no. 10, pp. 1341-1349, 2009.

[20] Z. Zhang, Y. Qin, X. G. Zhuang, G. Q. Li, "Porosity and Permeability Models for Coals Using Low-Field Nuclear Magnetic Resonance," Energy \& Fuels, vol. 26, no. 8, pp. 5005-5014, 2012.

[21] X. D. Zhang, Z. G. Du, P. P. Li, "Physical characteristics of high-rank coal reservoirs in different coal-body structures and the mechanism of coalbed methane production," Science China-earth Sciences, vol. 60, no. 2, pp. 246-255, 2017.

[22] J. L. Zhao, H. Xu, D. Z. Tang, "A comparative evaluation of coal specific surface area by CO2 and N2 adsorption and its influence on CH4 adsorption capacity at different pore sizes," Fuel, vol. 183, pp. 420-431, 2016.

[23] Y. P. Zhang, Y. F. He, Z. M. Yang, H. K. Guo, "Application of Nuclear Magnetic Resonance Technology in Evaluation of Coalbed Methane Reservoir," Journal of Oil and Gas Technology, vol. 32, no. 2, pp. 277-279, 2010. 